\title{
Denture Labeling Using QR Codes. A Simplified Technique
}

\section{Identificación de dentaduras completas utilizando códigos QR. \\ Una técnica simplificada}

\author{
Rodrigo A. Jiménez DDS1 \\ 1. Prosthodontist. Adjunt Professor. Graduate Prosthodontics. University of Costa Rica School of Dentistry. \\ Correspondence to: Dr. Rodrigo A. Jiménez - rjimenezcorrales@gmail.com \\ Received: 1-VII-2017 \\ Accepted: 24-VIII-2017 \\ Published Online First: 29-VIII-2017
}

DOl: https://doi.org/10.15517/ijds.v0i0.30389

\section{ABSTRACT}

Denture identification procedures have multiple benefits for denture wearers. These include prevention of losing or misplacing dentures and forensic identification of victims. A simplified inclusion technique is fully described to label dentures with QR code prints.

\section{KEY WORDS}

Denture labeling; Denture QR codes; Denture identification techniques.

\section{RESUMEN}

Los procedimientos de identificación de dentaduras completas tienen muchos beneficios para los pacientes. Estos incluyen la prevención de la pérdida o confusión de las prótesis y la identificación forense de las víctimas. Se describe en forma detallada una técnica simplificada para identificar dentaduras con códigos QR.

\section{PALABRAS CLAVE}

Etiquetado de dentaduras; Dentadura códigos QR; Técnicas de identificación de dentaduras. 


\section{INTRODUCTION}

Denture labeling has been recognized as a very important procedure for several reasons. Complete denture users comprise a population segment that is statistically associated to an older age group. This fact suggests that many of these patients show diminished cognitive and motor functions, memory loss or dementia. Also, many of them live in old age institutions, either full time or part time. Additionally, there might be a high incidence of health problems that may require hospitalizations. It is common under these circumstances to expect loss of removable prostheses or confusion regarding who they belong to. For this reason, the placement of identification elements within the dentures will simplify the caretakers' work and notably reduce the risk of denture loss for the patients. Denture labeling has also been recommended in forensic sciences as an adequate way to identify fatalities during catastrophic events (1). For these reasons, several countries require by law the labeling of dentures (2).

There have been several techniques used to identify dentures. These are classified into two separate categories, surface and inclusion techniques $(3,4)$. Surface marking techniques are often scratched, engraved or written on the surface of the denture. Many times they are covered with a polymer or left as a concavity or convexity. These techniques if applied on the external surface of the prosthesis can retain microorganisms or food debris and be uncomfortable to the intraoral tissues. If embossed on the intaglio as a bas-relief, there has been evidence associating it with malignancy because of constant tissue irritation (5).

Inclusion techniques, on the other hand retain the markings within the denture base material. There are various techniques to accomplish this including printing the patient's name on a piece of laminated paper or parchment paper, labels (6), stainless steel strips (7), lenticular cards (8), PMMA bars (9), laser etching (10), electronic microchips (11), photographs (12), radio frequency identification tags (13) or lead foil (14). Any of these objects are placed inside the denture base and covered by either heat cured acrylic during the denture processing, or afterwards with transparent auto polymerizing resin.

Recently, barcode technology has become available to most people. Barcode generator apps are very common on the internet and this technology allows for fast optical reading with smart phones. Standard UPC barcodes as well as QR matrix barcodes can contain much larger amounts of information than regular text. This fact makes it ideal to use as denture labeling and for this reason have been used for several years (15).

QR codes are very common in daily life and most people are exposed to them in the media on a daily basis. QR code stands for Quick Response code and is a two dimensional barcode created in Japan in 1994 for the automotive industry. It is formed by black squares arranged on a square grid. It has a white background and can easily be optically read with an imaging device such as the camera of a smart phone that has the appropriate program installed. It can hold large amounts of information, up to 4,296 alphanumeric characters (16). This characteristic and the fact that it is easily generated and read makes it ideal to use in denture labeling.

\section{TECHNIQUE}

There are several QR generator applications on the internet. Most of them are free of charge since QR Code technology is freely licensed if the standards are followed. 
Information placed in the code should include at least:

Name of the patient Identification number

Telephone number of a contact

Dentist's name and contact

Any relevant health information

With this information, a $Q R$ code is generated and printed. The size of the square for a maxillary denture should have a maximum of $22 \mathrm{~mm}$. per side, and it must be adjusted to the proper size of the denture. For a mandibular denture, the possibility of using a readable $Q R$ code depends on the size of the flange at the buccal shelf area. A minimum size of $17 \mathrm{~mm}$. per side is necessary. These dimensions are necessary because a very large code would be bent as the intaglio of the denture is convex and reading would be compromised. A much smaller code will also show difficulties during the scanning and reading.

The code should be printed with an injection type printer. Laser prints will smear with the monomer. It should be printed in parchment paper, cut to the proper size and set aside, making sure the front surface of the code is facing up. It is important to verify at this stage that the QR code is readable with a smart phone. If not, it will be useless inside a denture.

The QR code printout will be included in the denture during the packing of the acrylic as follows:

- Flask the denture in the usual manner (Fig.1).

- Eliminate wax making sure the models are very clean and apply tin foil substitute to all surfaces (Fig.2).

- Pack the acrylic in the flask and do trial pack with an acetate sheet (Fig.3).

- Cut with a clean sharp knife a piece of the excess flash of acrylic that will cover completely the code print and place it over it before closing the flask (Figs. 4, 5 and 6).

- Close the flask and process the denture as usual.

- Finish and polish the denture in the usual manner.

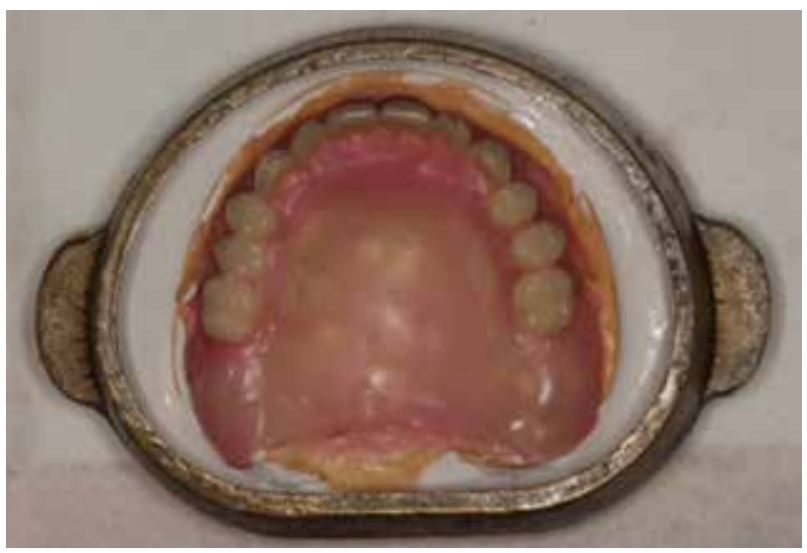

Fig. 1. Flasking of the denture.
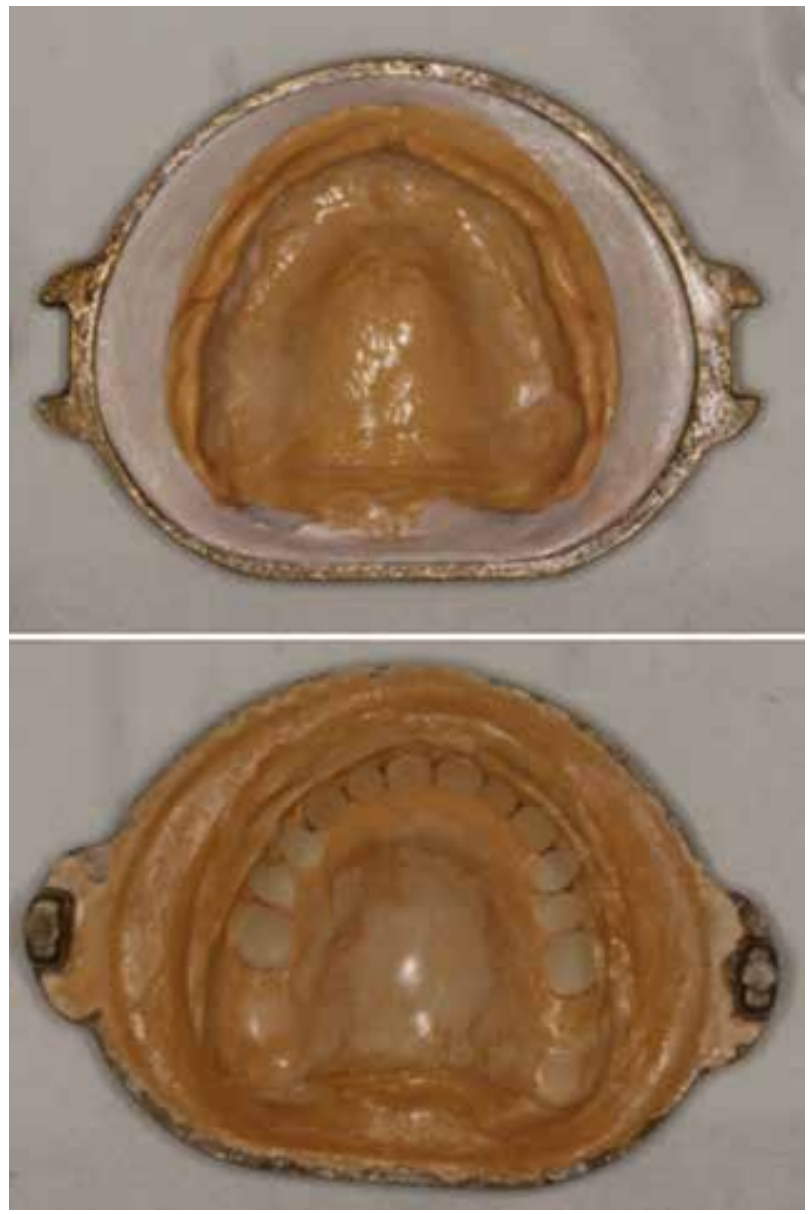

Fig. 2. Wax elimination and washing. 

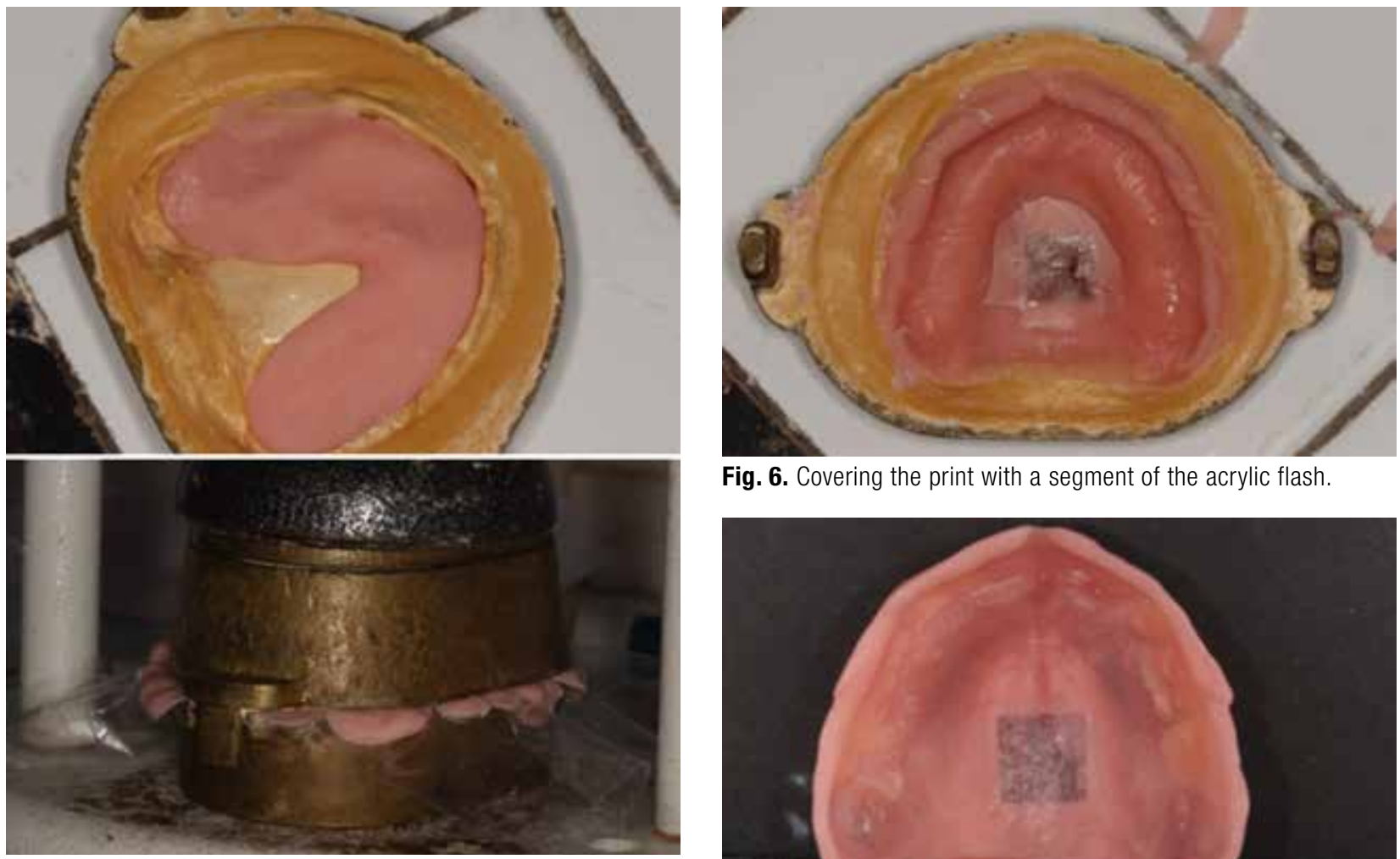

Fig. 6. Covering the print with a segment of the acrylic flash.

Fig.3. Packing the acrylic and trial pack.

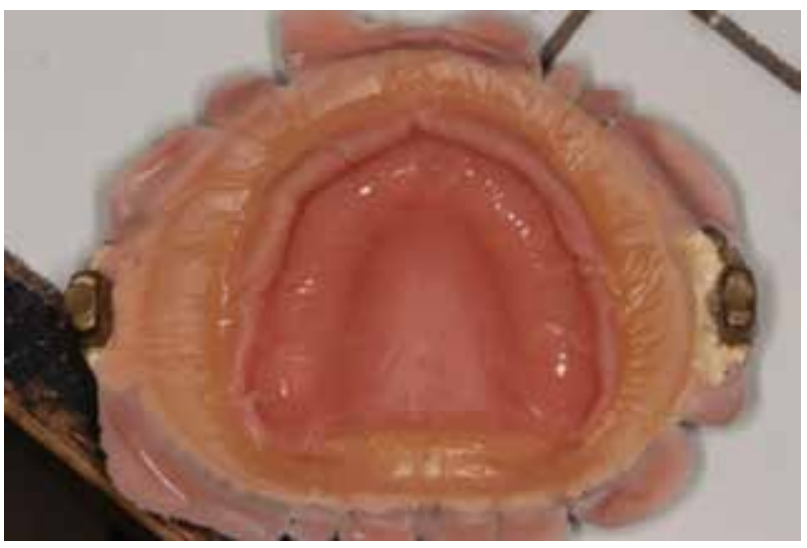

Fig. 4. Excess acrylic flash after trial pack.

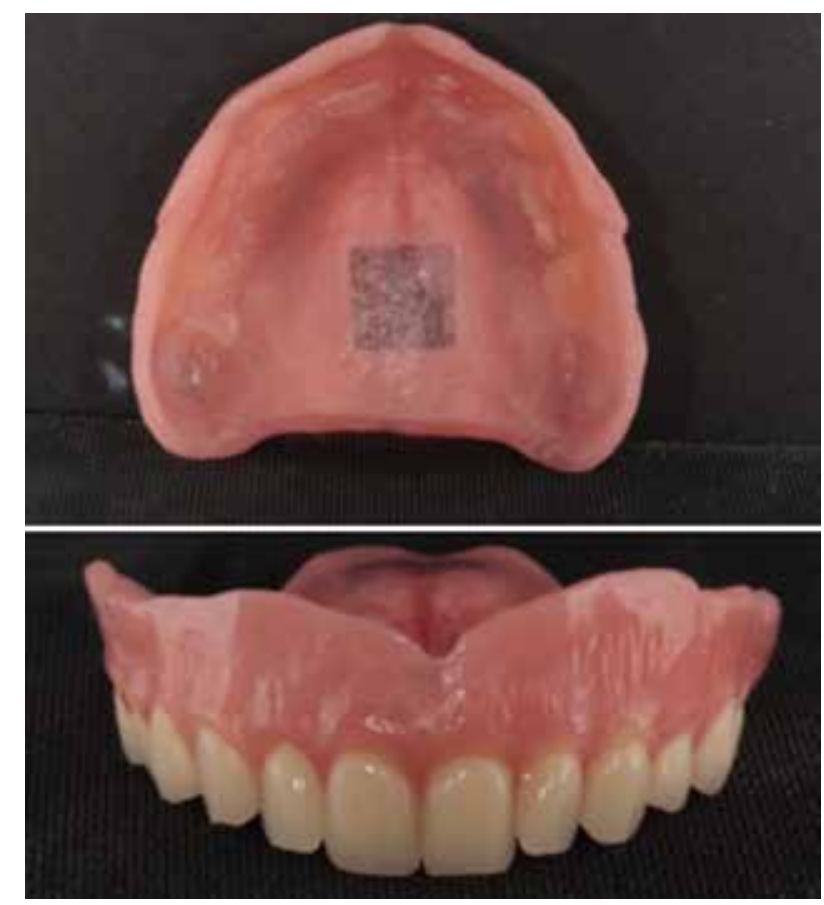

Fig. 7. Finished dentures.

\section{DISCUSSION}

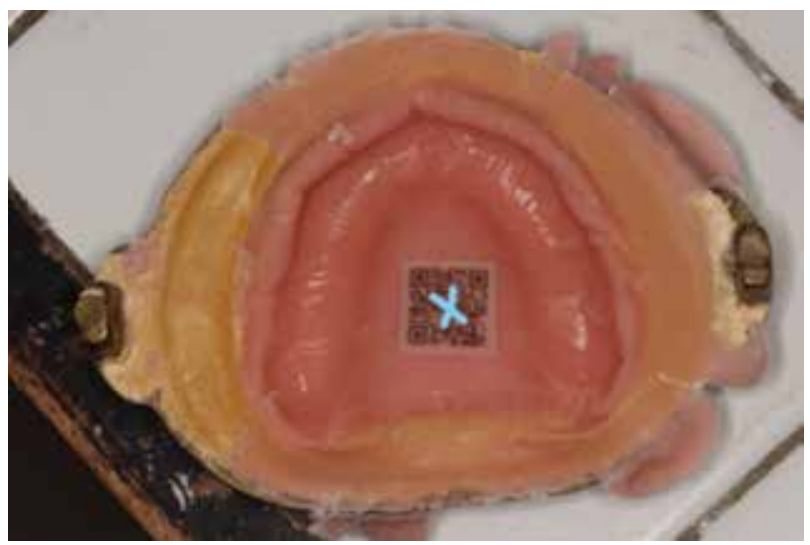

Fig. 5. Placing the print on the intaglio.

There is a wide difference in the use of denture identification procedures in different countries. In some areas they are mandatory, and in some others rarely performed. We feel that the reason why their use is not universal is a lack of information as to how to accomplish an easy and inexpensive labelling. It is however, a procedure that can considerably prevent a large amount problems for the patients. It is not difficult to imagine the impact on a patient's self- esteem and quality of life if he suddenly finds himself 
with a lost denture. Needless to say the financial impact of replacing a prosthesis and masticatory deficiencies will also negatively affect a person's well-being.

Additional benefits of labelling a prosthesis, as stated before, include victim identification in disasters or accidents, identifying lost or unconscious patients, providing relevant health information in emergencies.

This is why we believe all these benefits greatly outweigh the small additional efforts in identifying dentures and vehemently recommend every professional that constructs and delivers prosthesis to provide this additional benefit to all his patients.

\section{REFERENCES}

1. Gosavi S., Gosavi S. Forensic odontology: A prosthodontic view. J Forensic Dent Sci 2012; 4 (1): 38-41.

2. Alexander P. M., Taylor J. A., Szuster F. S., Brown K. A. An assessment of attitudes to, and extent of, the practice of denture marking in South Australia. Aust Dent J. 1998 Oct; 43 (5): 337-41.

3. Shepherd M. Automatic identification of dental appliances. Br Dent J. 1997; 182: 171-174.

4. Takahashi F., Koji T., Morita O. Durable method of denture identification. J Prosthet Dent. 1998; 3:28.

5. Matsmura H., Shimoe S. Incorporation of a cast, embossed identification plate into a partial denture framework. J Prosthet Dent 2002; 88: 215-6.

6. Thomas C. J. The role of the denture in identification: A review. J Forensic Odontostomatol 1984; 2:13-6.
7. Stavrianos C.H., Petalotis N., Metska M., Stavrianou I., Papadopoulos C. H. The value of identification marking on dentures. Balk J Stom 2007; 11:212-6.

8. Colvenkar S. S. Lenticular card: A new method for denture identification. Indian $\mathrm{J}$ Dent Res 2010; 21:112-4.

9. Ryan L. D., Keller J. B., Rogers D. E., Schaeffer L. Clear acrylic resin T-bar used in denture identification. J Prosthet Dent 1993; 70:189-90.

10. Ling B.C., Nambiar P., Low K. S., Lee C. $\mathrm{K}$. Copper vapour laser ID labelling on metal dentures and restorations. J Forensic Odontostomatol 2003; 21:17-22.

11. Rajan M., Julian R. A new method of marking dentures using microchips. J Forensic Odontostomatol 2002; 20: 1-5.

12. Anehosur G. V., Acharya A. B., Nadiger R. K. Usefulness of patient photograph as a marker for identifying denture-wearers in India. Gerodontology 2010; 27 (4): 272-7.

13. Nuzzolese E., Marcario V., Vella G. Di. IncorporationofRadioFrequencyIdentification Tag in Dentures to Facilitate Recognition and Forensic Human Identification. Open Dent J 2010; 4: 33-6.

14. Kumar S., Banerjee S., Dwivedi H., Gupta T., Banerjee A. Personal identification using complete dentures. International Journal of Prosthodontics and Restorative Dentistry 2011; 1 (2): 132-5.

15. Nalawade S. N., Lagdive S. B., Gangadhar S., Bhandari A. J. A simple and inexpensive barcoding technique for denture identification. J Forensic Dent Sci 2011; 3 (2): 92-4.

16. Information capacity and versions of $\mathrm{QR}$ Code. (2017, August 20). Retrieved from http://www.qrcode.com/en/about/verion.html 